\title{
Ile Timi: the interface between traditional and vernacular architecture in Ile-Ife
}

\author{
C. O. Osasona \& F. O. Ewemade \\ Department of Architecture, Obafemi Awolowo University, \\ Ile-Ife, Nigeria
}

\begin{abstract}
Ile-Ife is world-famous for its sculptures, and for the pivotal role it plays in defining black culture. It boasts of notable examples of Nigerian traditional, vernacular and metropolitan architecture. The paper discusses Ile Timi, a building strategically located with respect to Ife mythology and local building practices. It highlights its peculiarities at the interface of the transition from the traditional to the clearly-distinguishable vernacular. Ile Timi authenticates traditional building practices, while accommodating advantages of the new. The work also examines evolutionary trends in space-use and inherent meaning, to underscore the significance of such buildings, and concludes that more should be done to conserve them; apart from their heritage value, they have potential for boosting local tourism.

Keywords: traditional architecture, vernacular architecture, Ile Timi, Ile-Ife, heritage architecture, Ife mythology, black culture, space-use, building practices, covert symbolism.
\end{abstract}

\section{Introduction}

The ancient Yoruba town of Ile-Ife has long been on the world map, as it is associated with exquisite archaeological finds, ethnological debates and the general promotion of negritude. Many black peoples in the diaspora continually seek links to this town, credited with being the cradle of the Yoruba race (Biobaku [1]) and a lead player in defining what constitutes "black culture".

Specifically, Ife bronze and terracotta sculptures have engaged the attention of archaeologists, art historians, anthropologists and other scholars, for nearly a century; their virtues have long been extolled by explorers such as Leo Frobenius 
(who credited the Greek civilization with their production); Olomola [2] claims he had referred to Ile-lfe as the "far-famed and mysterious Atlantis". Closely allied to this culture of art-in-the-round (also featuring wood- and calabashcarving and pottery), is a rich tradition of performing arts, bead-making, clothweaving-and-dyeing, and blacksmithing (Osasona and Hyland [3]).

Ile-Ife is typical of most traditional Yoruba towns: the traditional ruler (Ooni)'s residence is roughly centrally-located, with the houses of his subjects defining concentric rings of relative socio-political importance around it, and with major public circulation arteries radiating from this hub. (In a general sense, the wards appear to be delineated by these major arteries, many of which take their source from the palace; the highest-ranking chiefs have their homes located closest to the ruler, with the hierarchy generally diminishing, the farther from the palace (Ojo [4] and Obateru [5]). Architecturally, too, the town is typical of very old Yoruba cities now in the throes of critical socio-spatial transformations, in a bid to cope with the imposed and increasingly complex demands of a globalized world. As such, in physical terms, the town is characterized by a pot-pourri of archetypes comprising samples of near- pristine Yoruba traditional buildings (though now limited), vernacular variants and metropolitan-style architecture.

Close to the Ooni's palace, there are ancient buildings of cob construction; most of these are nearly a century-old, and many, derelict; in the next concentric ring (and interspersed with less pretentious buildings) are a few samples of residences in the Brazilian Style. These belong to traditional chiefs and other local elite who were exposed by travel (and had the means) to erect such buildings. More widespread, are examples of popularized adaptations of the Afro-Brazilian, followed by a varied landscape of hybrid modern construction in the suburbs.

This study aims to spotlight Ile Timi, a building important not only in Ife socio-political annals, but with significant historical connotations for a wider circle in Yoruba-land. However, the emphasis is on its phenomenal positioning on the architectural history time-scale. Just as Durham Cathedral in the United Kingdom is delicately poised at the inter-face of the Romanesque and Gothic, Ile Timi strategically overlooks popular Yoruba vernacular, while significantly harking back to the traditional. Yoruba architecture can only be properly appraised in the context of space-use and inherent socio-cultural meaning. So, in discussing Ile Timi, it is imperative that other classes of local building culture be examined, to provide an appropriate backdrop against which the building can be properly appraised. Such analyses are undertaken, citing a specific case in each of these styles: the traditional, Brazilian/ Afro-Brazilian and the vernacular.

\section{An overview}

\subsection{Traditional Yoruba architecture}

Many literary works have attempted to present varying aspects of the Yoruba traditional built environment to the world (Mabogunje [6]; Ojo [7]; Krapf-Askari [8]; Eades [9]; Osasona [10]; Osasona, [11]; Obateru [5]). Characteristically and 
traditionally, the Yoruba live in large urban groupings worthy to be classified "towns"; at the extended family level, in clusters referred to as agbo'le (referring more to sociological relationships than physical delineation of space), and also in family settings called idi'le. All three levels have implications for physico-spatial development: the first, defines the town morphology, well-expounded by Mabogunje [6] and Ojo [4]; the second, often accounts for ward delineations in a town. The basic socio-cultural unit at ward level is the agbo'le - this time, with the definition of a group of spaces (literally, a "flock of houses /habitable spaces") and predicated on the initial family or idi'le. Agbo'le is articulated as an impluvium-courtyard compound; where the family size is large, it could comprise several such impluvium-courtyards. The palace of traditional ruler is the peak of this architectural expression. It is usually a highly complex assortment of living spaces and courtyards, invariably set up on elevated ground (Obateru [5, pp.217-218]). The old Owo Palace is credited with having about 200 courtyards, and a land area of about 44 hectares (Ojo [12]).

Traditionally, building materials included earth, palm fronds, gbodogi leaves (sarcophrynium) and hardy timber (e.g. from the oil-palm and coconut trees). Table 1 shows material-use and techniques. Where earth was used, rendering with earth mortar and/ or slurry, was optional.

\subsubsection{Ile Obaloran}

Located within 150 metres of the Ooni of Ife's palace, this is a rambling, traditional building complex. It consists of five impluvium-courtyards and about 45 living/ storage spaces. The official residence of Obaloran, one of the most important chiefs in the Ife kingdom (Osasona [13], Osasona and Ogunfolakan [14]), it was originally entirely of cob construction, with typical undersized doorand window-openings. Reputed to be over a hundred years old, it is dangerously dilapidating. (By 1998, many of the walls had crumbled, and the gaps were boarded up with corrugated roofing sheets on timber. That notwithstanding, the incumbent Obaloran was still in residence, as it was still the official seat of the title (Osasona [13])). Typically, many of the original spaces were devoted to traditional deities, rituals and associated paraphernalia.

Fig. 1 shows the sprawling Obaloran family house. With typical steeplypitched hip-and-saddle roofs, it highlights the major characteristics of traditional building practice among the Yoruba. Peculiar to the Ifes, is the akodi-a meeting space within the building, constituting a rallying-point for a lineage group at ward level (Mills-Tettey [15]). In Ile Obaloran, the akodi was originally a commodious space, deployed around one of the main impluvium-courtyards, at the centre of the building; however, with the gradual depreciation of the building - and possibly as a concession to modernity - its roles have been transferred to a relatively new, discrete, two-storey purpose-built structure, on adjoining Obaloran family land. The akodi is used for family deliberations, adjudications, ceremonies and more immediate domestic activities like story-telling. 


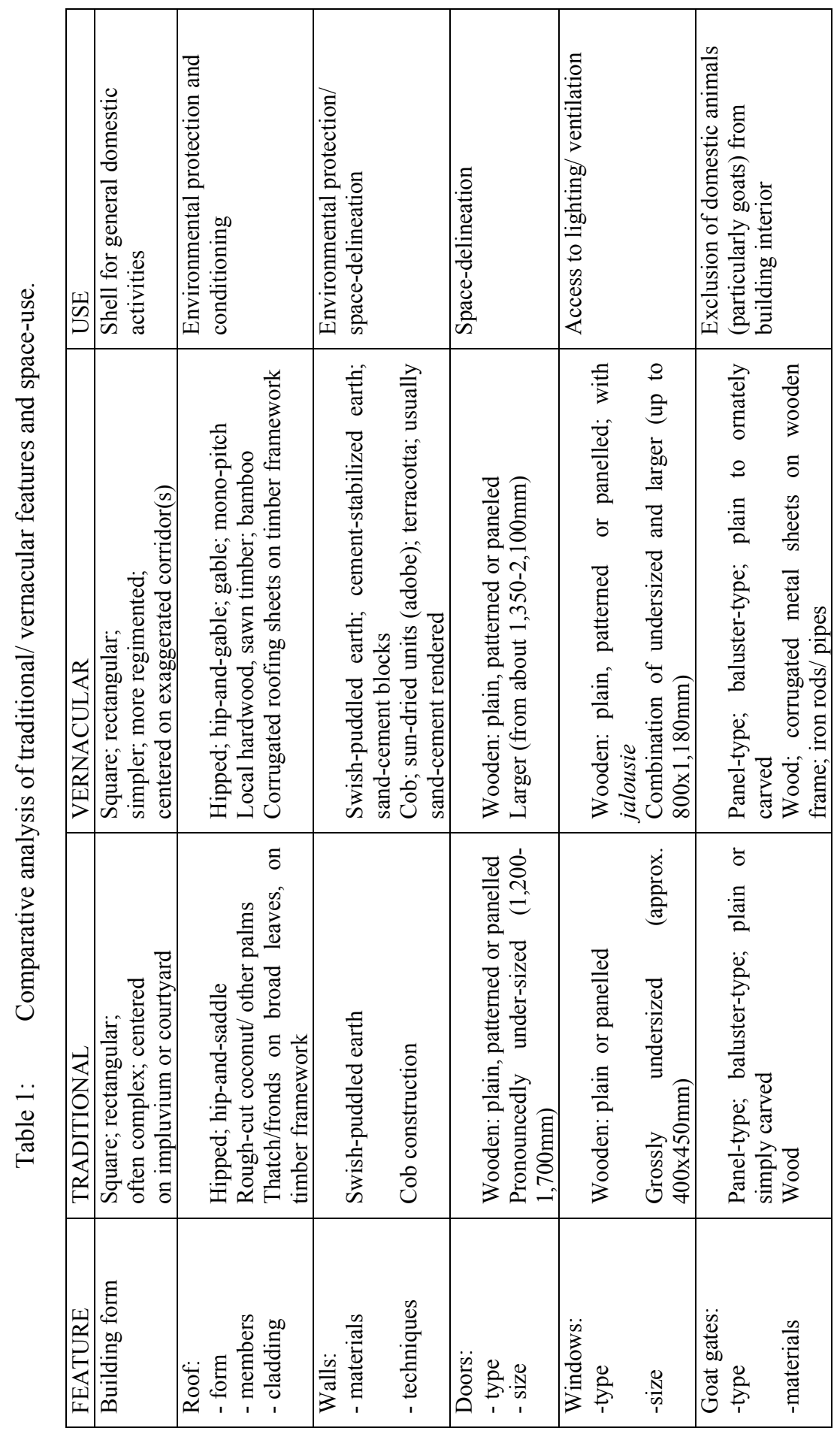

WIT Transactions on The Built Environment, Vol 118, (C) 2011 WIT Press www.witpress.com, ISSN 1743-3509 (on-line) 


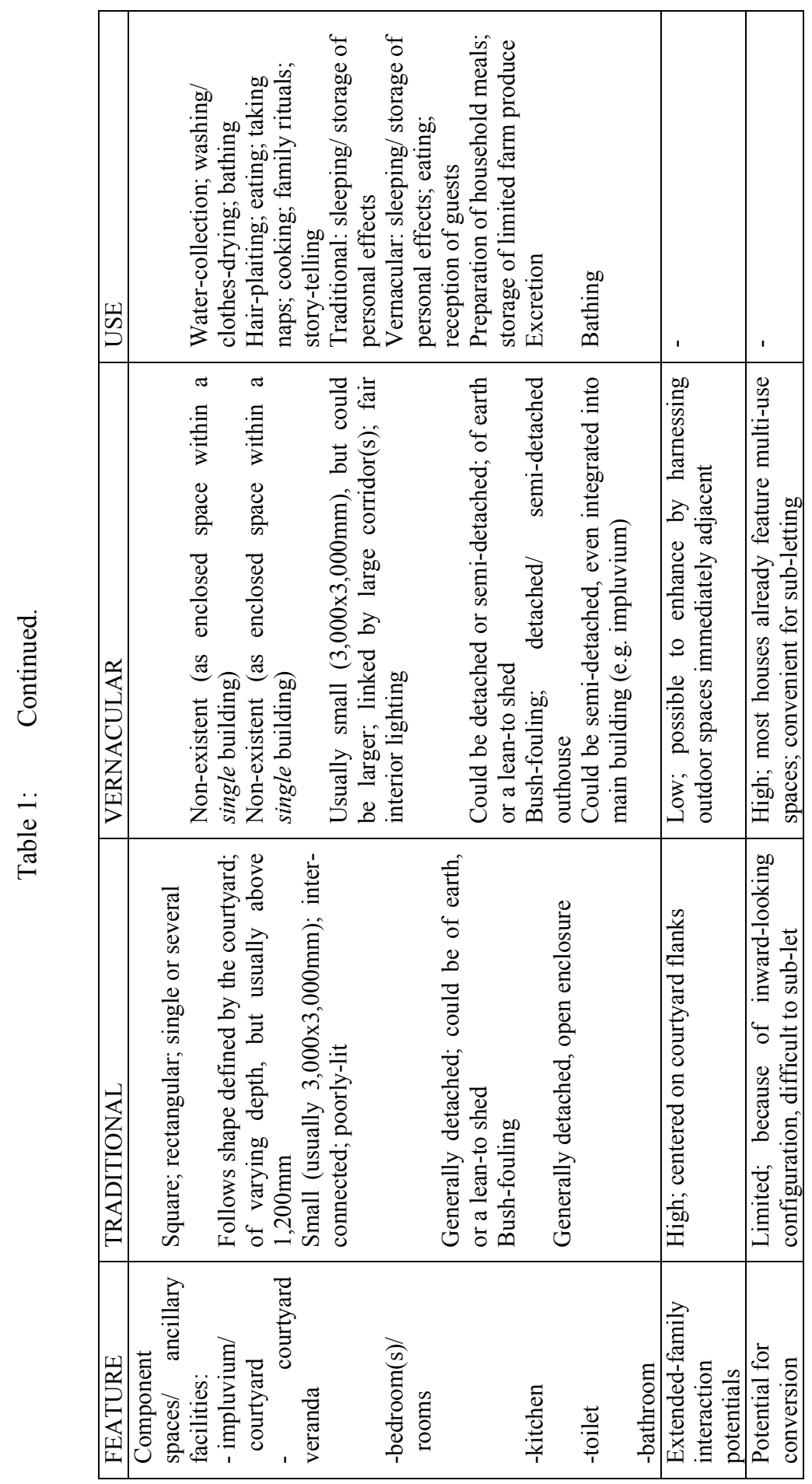



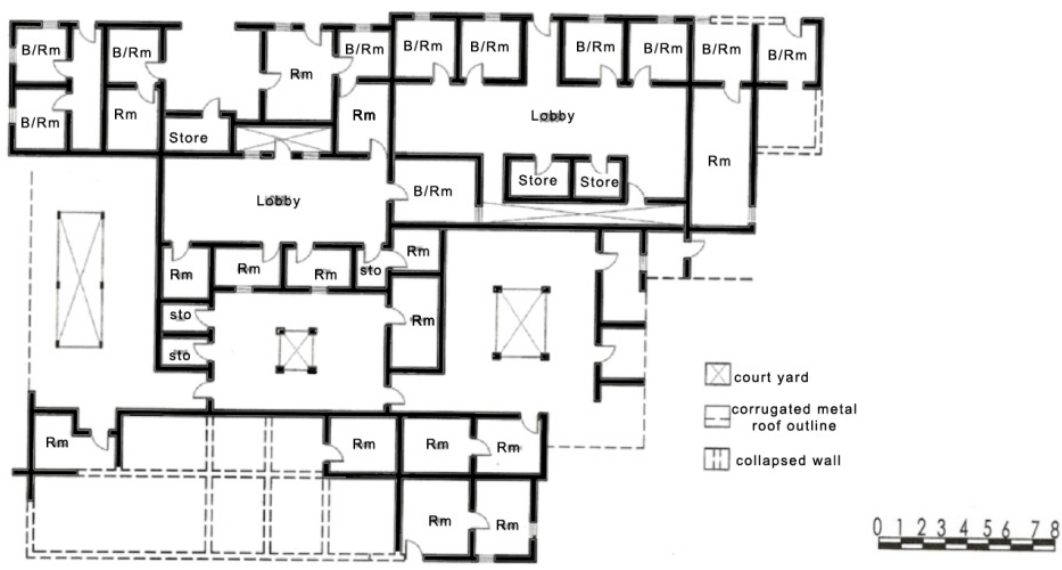

Figure 1: Ile Obaloran: floor plan.

\subsection{Brazilian/ Afro-Brazilian architecture in Nigeria}

The "Brazilian Style" has its roots in the building practices engaged in by African slave labour in Bahia, Brazil. These slaves were responsible for defining much of the Bahian cityscape - particularly with respect to its Baroque-type churches (even though they were predominantly Muslim) (Hallen [16]). After repatriation to West Africa, they peddled the building construction and commercial skills acquired while in slavery.

Apart from personal residences, the specialty of these emancipado craftsmen was the building of churches and mosques. First-generation "Brazilian" construction was characterized by heavy ornamentation, reminiscent of Baroque practices. In a typical house, habitable space was deployed to both sides of an exaggerated, centrally-located corridor (passagio); buildings were invariably storeyed, with complex garret-roof configurations. Typically too, in a homestead, conveniences and the kitchen were fully-detached and back-of-the-house. It was also the norm to integrate shops within the dwelling. With time (and geographic diffusion), less attention has progressively been accorded ornamentation; this has given rise to several other generations of the original building craft, each distinguished by dwindling decoration, and commonly termed "Afro-Brazilian" (Osasona [17]).

\subsubsection{The Olayinka House (Ile 'Layinka)}

Situated within 200 metres of Ile Obaloran - and thus, still within the vicinity of the Ife palace - this is a second-generation Afro-Brazilian building. The personal residence of Samuel Johnson Olayinka Fatanmi (alias “S. J. Ola the Great"), the enigmatic Ife man-of-many-parts, it was constructed in 1928. In general design and aspect, it was to reflect not only S. J. Olayinka's affluence, but his avantgarde taste in architecture, acquired from his frequent business trips to Lagos. As such, it features ornate mouldings in stucco, the characteristic double-loaded 
corridor (Marafatto [18]), and detached outhouses; also, it originally had an attic. In 1985, twelve years after Olayinka's demise (and as a result of poor maintenance of its timberwork), the attic was brought down, and the building's roof re-configured (Osasona and Ogunfolakan [14]).

Like construction pre-dating the Modern Movement, the Olayinka House (fig. 2) is over-structured: massive adobe brick walls, about $750 \mathrm{~mm}$-thick, are earth-plastered and painted, with ornamental niches worked into the façade. Interior spaces are minimally lighted, and essentially deployed symmetrically. Timber was extensively used for window shutters, portal embellishment and as "ventilation screens" (an accessory to a window-opening, to help regulate the amount of air that comes into a room; it is moveable in a vertical plane, and usually decorative).
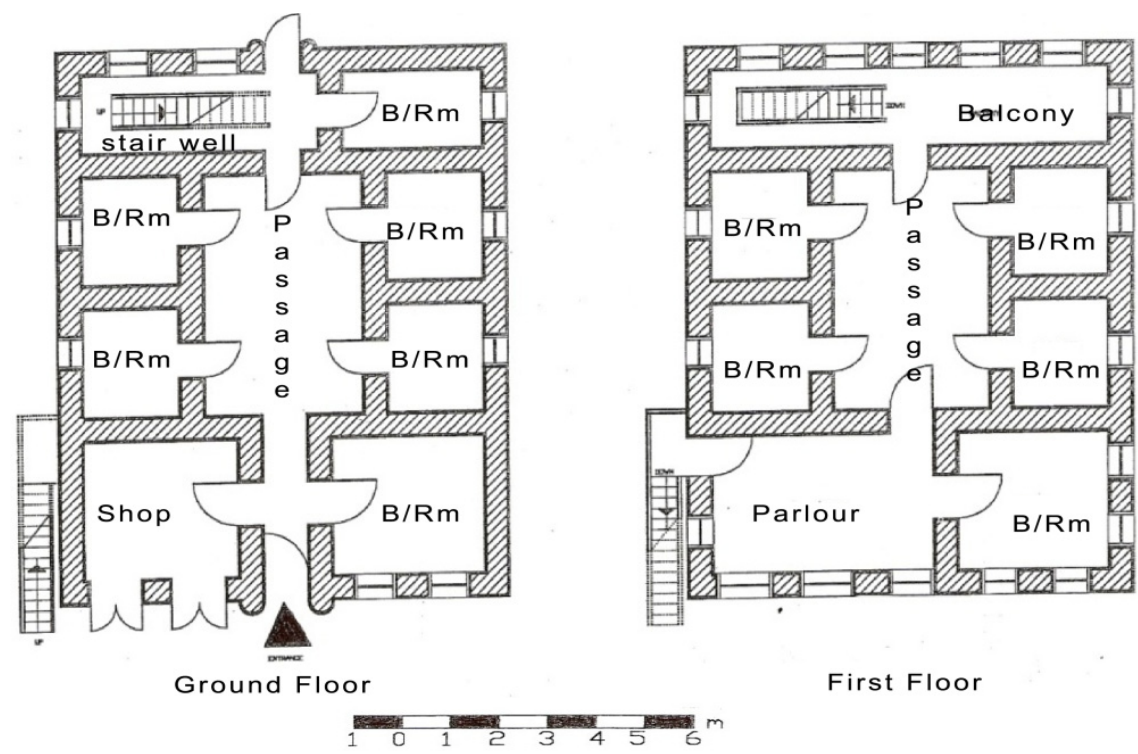

Figure 2: $\quad$ Olayinka house, floor plans.

Though not a designated chief per se, Olayinka's social standing was at par with that of the high-ranking chiefs of his time. His residence typified the emerging style of building among Ife's nouveau riche - the class of chiefs and well-to-do indigenes - who, by virtue of their importance in the local sociopolitical arena, lived fairly close to the Ooni's palace.

\subsection{Yoruba vernacular architecture}

The term "vernacular" can be applied to various phenomena, basically to depict a practice, not necessarily indigenous to - but widely-embraced by - the generality of the people in a limited geographical setting. It can refer to language, mode of dress, cuisine and, expectedly, architecture, among the possible options. 
Essentially, it is the product of cultural diffusion, whereby interacting cultures influence one another such that borrowed traits, ideologies and products become adopted, personalized and eventually, re-packaged as "indigenous" to the borrowing culture. Nigerian vernacular architecture is the product of the various ethnic building practices and forms, impacted by extraneous colonizing influences. In the north of the country, the extraneous influences include Arabic jihadist legacies, and the nation-wide colonial impositions. To the south, they are essentially colonially-facilitated, but clearly observable as British or Brazilian.

The popular Yoruba vernacular building model displays a simplified floor plan, symmetrical about a longitudinal axis, with living spaces flanking an extralarge, multi-purpose passageway; conspicuously, it is no longer predicated on a courtyard, and is discrete. It very often sports a covered entrance veranda, occasionally with a similar space at the rear; each of these constitutes a transition zone between indoor semi-private and outdoor public or semi-public spaces.

Though usually single-floor, there are multi-level variants of the Yoruba folk dwelling; the latter is highly-favoured for tenement housing. In either case, materials are indigenous (i.e. locally-available) and relatively inexpensive. The popular choices are adobe bricks, terracotta and sandcrete blocks; generally, it has become the norm to cement-plaster walls and roof the building with corrugated metal sheets. Ornamentation, where it exists, is now limited (usually just on panelled doors and veranda columns. Also in the spirit of change, roofs are now more gabled (or hip-and-gable) than hipped. Sheds (serving as cooking spaces) and conveniences continue to favour a totally-detached back-of-the house deployment in bungalow-types, but could be semi-detached (though also located at the rear) in storeyed versions. In its entirety, the Yoruba folk (vernacular) built-form leans heavily on Brazilo-Portuguese antecedents (though an occasional raised approach, recalls British colonial practice).

\subsubsection{Ile Aguro}

Even though, hitherto, the term ile has been used to convey a house, it should be noted that it is abbreviated from "idi ile" (idi'le) and can also be expanded to mean "the root of a lineage or house". Ile Aguro here, refers to a large family compound, comprising 12 discrete building units. Situated about half a kilometer from the palace, the compound is a loose assortment of dwellings and ancillary facilities. Apart from the usual ones, other homestead components include watertaps, a well, common open spaces and graves (Osasona [19]). Fig. 3 shows the floor plans of two of the buildings in Ile Aguro compound. In the building on the right (fig. 3(b)), the introduction of wall projections halfway down the corridor creates an unusual and interesting illusion of a semi-apartment configuration; the building to the left is also a-typical in its double, parallel corridors.

\subsection{Meaning in Yoruba built-form}

Traditionally, all over Africa, built-form has been imbued with meaning transcending the overt. In Nigeria, such symbolism has been associated not only with spatial configuration, but also with materials and techniques (Osasona [20]). 

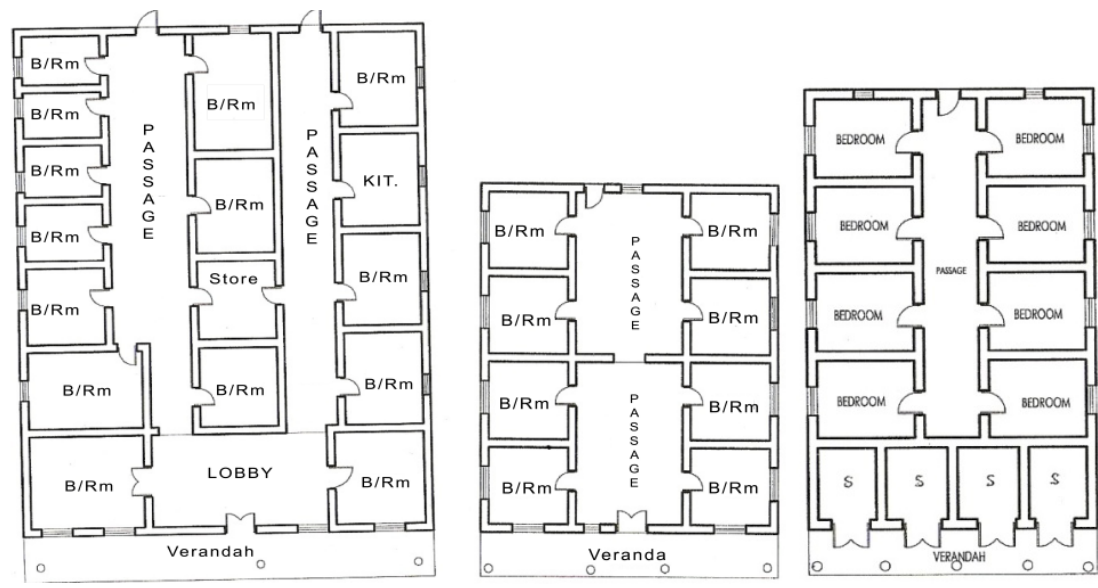

Figure 3: $\quad$ Left (a) and middle (b), Ile Aguro, floor plans; right (c), Alikin Compound, showing floor plan of mixed-use building.

Among the Yoruba, the impluvium-courtyard has assumed great significance beyond its utilitarian value. For example, related to it among the lfe, is the akodi which ordinarily serves routine purposes, but more significantly, is for social intercourse among all descendants of the lineage head; in the past, it was so socio-culturally important that it had to be integrated into the building design. Bedrooms were private space, and even at the family level, access was very limited - particularly to that of the family head; where privileged access was granted to persons outside the immediate family, it was for reasons of "secret" transactions (such as performance of rituals or money transfers).

In vernacular architecture, limited and necessarily different expressions of covert symbolism still exist. Here, functional expedience has tended to condition space-use: the extra-large corridor now services activities that traditionally took place in the flanking veranda-space of the impluvium-courtyard (see table 1), particularly during unfavourable weather. In large cities like Lagos, tenement housing is common, and has become time-related in space-use. Spaces are more flexible, changing articulation and use, as dictated by time-conditioned family exigencies. As such, in a two-bedroom "room-and-parlour" allocation, one of the spaces serves as the "master-room" (where the parents sleep, store foodstuffs, clothes and family treasures), while the other, the "general space", serves (during the day) as living-/dining-room, and at night (with furniture pushed against the walls) as sleeping area for the rest of the family; in the morning, this space is restored to its daytime status, before parents head for work and children, to school (Osasona [17]). In more rural settings, a family could account for a whole building; in fact, a compound, comprising several buildings, invariably belongs to people related by blood. Here, in-between spaces are important: they provide space for all manner of domestic activities and social interactions, and house 
utilities - as diverse as wells and burial grounds! Also, the living-trading lifestyle of the Yoruba is catered for, by integrating shops into the residence (fig. 3(c)).

\subsection{Features and space-use in traditional/ vernacular Yoruba architecture}

Though morphologically, Yoruba built-form has undergone (and is still undergoing) clearly-distinct changes, essentially, the socio-cultural content of the typical house remains unchanged. Table 1 compares the characteristic features of traditional and vernacular architecture, and outlines their uses.

\section{Analysis of Ile Timi}

\subsection{Socio-physical history}

The building is less than 100 metres, as the crow flies, from the Ife palace. It is set on a slight eminence, and is part of a bigger family complex - Agbo'le Timi. Communal labour (owe), from the extended family and neighbours, was used in its construction. The original nucleus was reportedly built during the First World War (i.e. between 1914 and 1918). At present, Ile Timi is a 12-room, singlestorey structure, with clear indications of its construction phases.

The house was built by Awoyele Adarierin (adarierin being a nickname meaning "he who beheads the elephant") - a renowned and wealthy hunter, who was also a pioneer of Islam in Ife and a cleric of the neighbourhood mosque. He was polygamous, and was reputed to have ruled his household well. An evidence of this latter statement was his "zoning" of their accommodation such that wives who got along well (generally peace-loving ones), were grouped together in their spatial allocations, while less amicable, volatile ones were separated from these. Reflective of typical organic traditional (and to some extent, vernacular) building practices, rooms were added on as the need arose. For example, the room for Famojure (a new wife from a wealthy family) was built when Awoyele was in the process of adding her to his harem; also, two additional rooms for grown sons were built (which now comprise the "boys' quarters" - a colonial legacy referring to a small, less pretentious accommodation provided by the colonials for retainers, and totally segregated from the main house (Osasona [17])). Because of its social history, Ile Timi is well-regarded in Ife and its environs. "Timi" is the official title of the traditional ruler of Ede, a town about 60 kilometers away from Ile-Ife. From popular local folklore - not, however, substantiated by such authorities on Yoruba origins and culture as Johnson [21] and Ojo [7] - Ede indigenes are said to have migrated from Ile-Ife; in fact, specifically from this compound. By implication, therefore, the first ruler of Ede is locally believed to have originated from this family. (However, Reverend Samuel Johnson, the writer of the oldest indigenous account of the origins of the Yoruba, reports that Ede was set up as a military security-post by the Alaafin of Oyo; even the Encyclopedia Britannica Online supports this, giving the name of the first commander-in-chief of the military camp as Timi Agbale). Nevertheless, the popular myth is locally upheld and - further imbuing the house with social 
prominence - it is commonly rumoured that the house is linked to the Ooni's palace by a tunnel!

\subsection{Morphology}

Today, Ile Timi is a complex of rectilinear spaces of different sizes, defining an irregularly-shaped mass, and preceded by a trapezoidal front yard, enclosed by a balustrade. Fig. 4, the floor plan of its present full articulation, outlines the two major stages of the house's development.

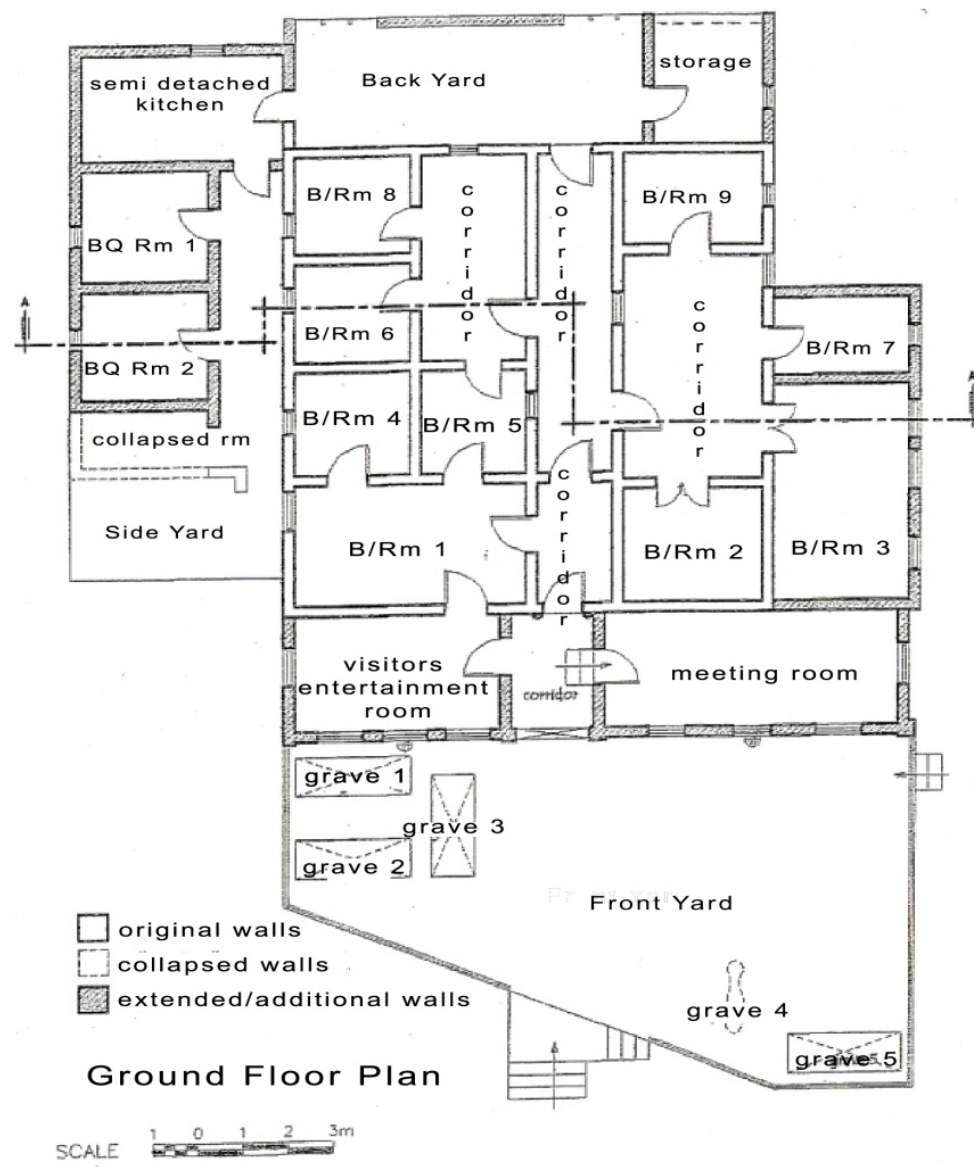

Figure 4: $\quad$ Ile Timi. Floor plan.

\subsubsection{Phase 1}

This stage defines the original configuration of the building. Against popular traditional building practices of the time - certainly unlike Ile Obaloran - this core unit is not articulated as an impluvium-courtyard. However, quite in 
keeping with traditional building floor plans, it is characterized by many interconnecting, indirectly-lighted spaces. Despite the noted absence of a courtyard, the Phase 1 stage of Ile Timi does not typify the vernacular, either. Even though corridors are clearly defined for circulation, in their actual configuration they are a-typical: basic vernacular floor plans invariably have a single, through corridor, servicing one-room deep habitable spaces, to the left and right; with more advanced later developments featuring a multiplicity of parallel corridors (as with Ile Aguro, shown in fig. 3(a)), each corridor retains its through nature, having at least one row of rooms opening out onto it, not back-to-back as indicated in the Phase 1 plan. At the very worst, the through course of such corridor(s) could be checked by a row of shops that might have been insinuated into the street façade of the building, rendering it mixed-use in utility, as in fig. 3(c).

\subsubsection{Phase 2}

The second phase of the evolution of Ile Timi witnessed expansion on all four sides. Part of the back regions of the homestead became annexed to the main house, as a dwarf-walled, but uncovered enclosure; to the right, it is flanked by storage space, while to the left, by a space linked to the main house, and used for cooking. This kitchen terminates extension to the left of the original building. Two additional rooms to the right (and two others separated by circulation space in front) complete the construction in Phase 2.

Ironically, with the new spaces on the right flank of the house, the original through-corridor in Ile Timi now resembles the typical, centrally-located Portuguese passagio, generally adopted by Nigerian vernacular. However, again, the similarity ends here, as the flanking spaces are deeper than unicellular, and inter-connect a-typically.

The expressed functions of the two new front rooms depict a concession to advancing social consciousness: earlier on, the lineage meeting space (the akodi) was in another part of the bigger agbo'le complex. However, with Awoyele's appreciated social status (and in keeping with vernacular practices) he designated front rooms (in Phase 2) for gatherings: the smaller, to lounging, and the larger (obviously a substitute for the defunct $a k o d i$ ) to extended-family interactions.

One of the most interesting features of the fully-developed Ile Timi, is the apparent lack of morbidity with respect to the interment of family dead. The front yard of the compound, shaped like a trapezium, is majorly characterized by the presence of tombstones marking the graves of departed family members. There are five of such graves in this area (fig. 4), with one of them no longer having a definable marker; in fact, present residents expressed (quite casually) that, given the rate of erosion of the soil-cover, the corpse may soon be exposed to view! Often, such tombstones and general grave definers are used as "ancillary facilities": for instance, washing may be draped over such tombstones, or they could be used as airing/ drying surfaces for maize or cocoa beans. This casual perception of spaces conventionally treated with a measure of reverence, is more a feature of Yoruba vernacular architecture than traditional. 


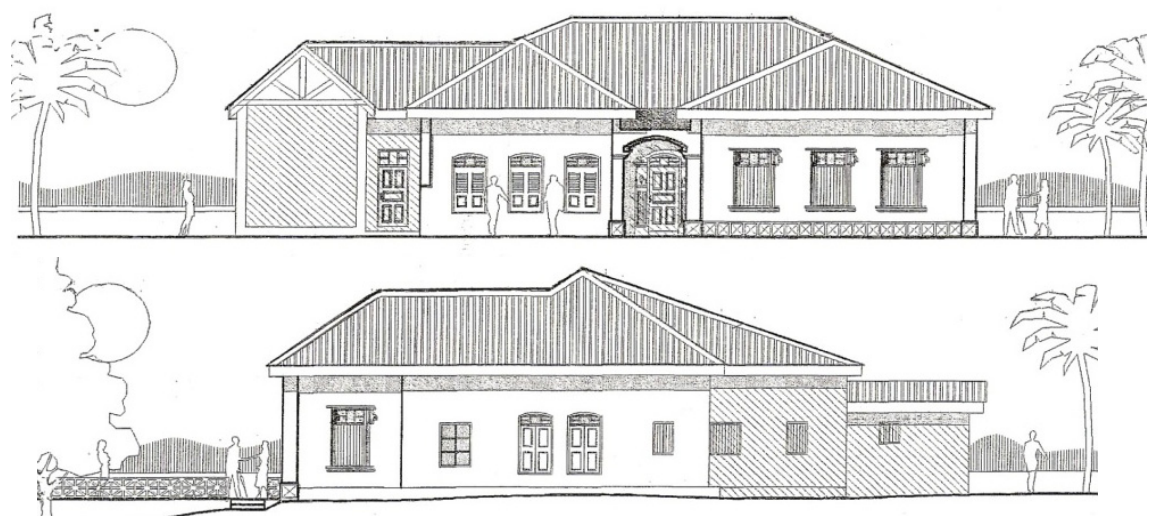

Figure 5: Ile Timi. Elevations: above, approach façade; below, right-hand flank.

\subsection{Building materials, techniques and features}

\subsubsection{Walls}

In the first phase of building, walls were of cob, while in the latter, of sun-dried bricks with earth as mortar for bonding; latterly, cement plaster was used to finish walls. With these techniques and materials, Ile Timi clearly accommodated both traditional and vernacular building practices common among the Yoruba.

\subsubsection{Roofs}

The original core of Ile Timi was roofed traditionally (i.e. palm fronds, over a layer of gbodogi leaves, spread on trusses of the palm tree, and with a restricted ceiling expanse of woven strips of frond). Corrugated metal sheets replaced palm fronds, during the expansion phase. (Even in rural satellite settlements of Ile-Ife, metal roofs have long been a feature of vernacular building).

\subsubsection{Doors and windows}

Doors and windows have also witnessed transformation. Under-sizing, particularly of windows, is a feature of the original building; some of these windows are pronouncedly less than $600 \times 600 \mathrm{~mm}$, and all timber shutters. (Typical Yoruba traditional houses either totally eliminated windows - admitting little light through the uncovered eaves, and from the courtyards - or had few, extremely small windows on the outer walls and, occasionally, on the inside; Osasona [22]). In Phase 2, larger doors and windows (and also glass) were introduced - all typical of the contemporary folk building culture of the time.

\subsubsection{Property fencing}

Traditional property-fencing in Yoruba-land manifested as wall segments linking substantive sections of the compound. Such short runs of wall were usually protected from rainwater erosion, by capping with battened-down sheaves of fronds. With vernacular practices, it has become a well-articulated feature: the 
emphasis now is clearly to de-limit property. With the new materials (and discrete construction), the greater part of such fencing still constitutes connecting flanges between different wings of a property; the frontage now presents a dwarf wall, 1,200 $\mathrm{mm}$ high, usually featuring a balustrade of ornamented balusters.

Characteristically, fencing in Ile Timi does not conform to the norm: though a wall segment defines a back yard, unlike common practice in the traditional, it does not provide total closure; prominent gaps allow free flow of traffic to other parts of the neighbourhood); also, a more characteristic fence section on the left flank has collapsed. In fact, as presently configured, the back regions of Ile Timi approximate the transition space between the semi-private central corridor and the semi-public back areas of Yoruba vernacular building. The frontage, with its low ornamental balustrade-fencing, is similarly typical of more recent popular folk practices.

\section{The value of Ile Timi}

According to Harvey, the chief quality that makes old buildings worthy of conservation is good craftsmanship, brought about by the integration of the craftsman and the architect in a single personality, and producing a satisfying unity in the product that has become extremely rare (Harvey [23]). The detailed analysis of Ile Timi, though not an attempt to spotlight exceptional craftsmanship, has undoubtedly highlighted its unique positioning in the transition from Yoruba traditional architecture to the vernacular; while the building apparently portrays a desire to move with the times, it has also demonstrated somewhat, a reluctance to totally break away from the past. This may be seen as a tacit endorsement of the things of both social and utilitarian value in the old, without jeopardy to the advantages (again social and utilitarian) to be gained from embracing the new.

Despite the intrinsic and explicit value attaching to Ile Timi, it is in an unfortunate state of disrepair. The descendants of Awoyele Adarierin are, for the most part, only occasional users of the main facility (having decided to settle in various other towns like Lagos and Ibadan); as such, they do not consider it worth their while to invest financially in its maintenance. Sadder still, is the fact that this situation is not peculiar to Ile Timi: it is the same unfortunate tale with Ile Oyinbo Moore, Ile Oladigbo, Ile 'Layinka, Ile Akogun and several others - all fine examples of le-Ife's vernacular architecture heritage, worthy of restoration and conservation. In 2001, an effort was made to initiate restoration work on the Olayinka House (Ile 'Layinka); since the project was financed from very meagre private funds, not much could be achieved (Osasona and Ewemade [24] and Osasona and Ogunfolakan [14]).

Ile Timi - and by extension, any other Ife building of an iconic stature, stemming from its historical associations, typological significance and/ or highlevel craftsmanship - has real economic potential. To begin to expound the various strategies for tapping such potential would be outside the scope of this paper. Suffice it to say that such countries as Egypt, the United Kingdom and Italy, have long explored the financial gains inherent in preserving man-made 
structures for tourist consumption. If Nigeria should take a cue from this, and invest in the restoration of the nation's many artifacts paying tribute to the nation's material culture, doubtless she would be the better for it - socially and monetarily.

\section{Submission}

Ile-Ife's significance to the Yoruba - and to blacks, in general - has been discussed as being multi-faceted, one of the most celebrated aspects being its material culture. In its various brands of architecture, it is typical of most Yoruba towns. A significant proportion of the builtscape has been described as being dominated by buildings whose antecedents can be traced to an inter-marriage between the traditional impluvium-courtyard typology, and British colonial and Brazilian building influences. Ile Timi, the focus of the paper, has been seen to be a-typical when viewed strictly from the purely traditional or purely vernacular stand-point; comparisons with local buildings in the different typological moulds, attest to this. It has, thus, been seen as being at the interface of the two (i.e. straddling the two worlds) and as such, classified as being singular.

Apart from the previously-cited real economic advantages of preserving buildings like Ile Timi, there are several other benefits, of a social nature, inherent in such a practice. There is the inestimable value of leaving historically(or otherwise) worthy buildings to posterity: where a culture has been careless in its attitude to such monuments, it implies a trivializing of its heritage, and an eventual situation in which such a society becomes totally bereft of physical landmarks imbued with socio-cultural identity. With today's often intimidating and aggressive architectural forms, the welcome visual relief such an architectural relic could produce would be akin to serendipity.

It is, therefore, in the best interest of Ile-Ife (and Nigeria, in general) for buildings such as Ile Timi to be given a new lease of life. The very limited experience with the re-furbishing of Ile Olayinka, served as an eye-opener to the potentials of such an intervention for streetscape enhancement (and by extension, city-centre upgrading), property-value appreciation and social re-definition, among likely fall-outs. It is quite acceptable practice, worldwide, for government efforts to be complemented by those of NGOs. However, for the present general relative unconcern to persist is to, not only endanger such heritage buildings, but to also run the risk of the nation not having any material heritage to speak of.

\section{References}

[1] Biobaku, S., Origins of the Yoruba, Federal Information Service: Lagos, 1955.

[2] Olomola, I., Ife before Oduduwa (Chapter 3), The Cradle of a Race: Ife from the Beginning to 1980, ed. I. A. Akinjogbin, Sunray Publications: Port Harcourt, p. 54, 1992.

[3] Osasona, C. O. \& Hyland, A. D. C., Colonial Architecture in Ile-Ife, Nigeria, Bookbuilders, Editions Africa: Ibadan, p. 45, 2006. 
[4] Ojo, G. A., Yoruba Palaces, University of London Press: London, 1966.

[5] Obateru, O. I., The Yoruba City in History, Penthouse Publications (Nig.): Ibadan, 2006.

[6] Mabogunje, A. L., Yoruba Towns, Ibadan University Press: Ibadan, 1962.

[7] Ojo, G. A., Yoruba Culture, University of London Press: London, 1967.

[8] Krapf-Askari, E., Yoruba Towns and Cities, Oxford University Press: Oxford, 1969.

[9] Eades, J. S., The Yoruba Today, University of Cambridge Press: Cambridge, 1980.

[10] Osasona, C. O., Transformations in the traditional Yoruba dwelling: a casestudy of Ile-Ife. Journal of Environmental Technology, FUTA, 1(1), pp. 1$15,2002$.

[11] Osasona, C. O., Ornamentation in Yoruba Architecture, Bookbuilders, Editions Africa: Ibadan, 2005.

[12] Ojo, G. A., Yoruba Palaces, University of London Press: London, p.27, 1966.

[13] Osasona, C. O., Transformations in the traditional Yoruba dwelling: a casestudy of Ile-Ife. Journal of Environmental Technology, FUTA, 1(1), p. 3, 2002.

[14] Osasona, C. O. \& Ogunfolakan, B. A., S. J. Ola the great: the strong man of Ife. The Nigerian Field, (68), pp. 18-32, 2003.

[15] Mills-Tettey, R., The layout and transformation of some traditional Yoruba compounds at Ile-Ife, Nigeria. Studies in Environmental Design in West Africa, 2, 1992.

[16] Hallen, B., Afro-Brazilian mosques in West Africa. MIMAR 29: Architecture in Development, Concept Media Ltd.: Singapore, 1988.

[17] Osasona, C. O., From traditional residential architecture to the vernacular: the Nigerian experience. Online http:www.mudonline.org/ aat/2007_documents/AAT_Osasona. 2007.

[18] Marafatto, M., Nigerian Brazilian Houses, Istituto Italiano Cultura: Lagos, 1983.

[19] Osasona, C. O., Transformations in the traditional Yoruba dwelling: a casestudy of Ile-Ife. Journal of Environmental Technology, FUTA, 1(1), p. 4, 2002.

[20] Osasona, C. O., From traditional residential architecture to the vernacular: the Nigerian experience. Online http:www.mudonline.org/aat/ 2007_documents/AAT_Osasona. Pp. 17-19, 2007.

[21] Johnson, S., The History of the Yorubas, CSS Limited: Lagos, p.156, 1921 (2001 edition).

[22] Osasona, C. O., Transformations in the traditional Yoruba dwelling: a casestudy of Ile-Ife. Journal of Environmental Technology, FUTA, 1(1), p. 8, 2002.

[23] Harvey, J., Conservation of Buildings, John Baker Ltd.: London, 1972.

[24] Osasona, C. O. \& Ewemade, F. O., Tentative steps in architectural conservation and restoration: the Olayinka House, AARCHES Journal, 2(1), pp. 50-60, 2002. 